\title{
Integrated surveillance for prevention and control of emerging vector-borne diseases in Europe
}

J C Semenza (Jan.semenza@ecdc.europa.eu) ${ }^{1}$, H Zeller $^{1}$

1. European Centre for Disease Prevention and Control, Stockholm, Sweden

Citation style for this article:

Semenza JC, Zeller H. Integrated surveillance for prevention and control of emerging vector-borne diseases in Europe. Euro Surveill. 2014;19(13):pii=20757.

Available online: http://www.eurosurveillance.org/ViewArticle.aspx?Articleld=20757

World Health Day, celebrated on 7 April, marks the anniversary of the founding of the World Health Organization (WHO) in 1948. This year, vector-borne diseases which are transmitted mainly by bites of vectors such as mosquitoes, ticks and sandflies are highlighted as a global public health priority. This issue of Eurosurveillance focuses on vector-borne diseases and their impact on public health in Europe and other parts of the world such as the recent outbreaks of Chikungunya fever in the Caribbean and Zika virus fever in the Pacific [1-6].

\section{Mosquito-borne diseases \\ Dengue and malaria are important mosquito-borne viral diseases, often also referred to as 'tropical' dis- eases. Globally, dengue is the most common mosquito- borne viral disease, with an estimated 390 million infections per year and $40 \%$ of the world's population at risk [7]. While interventions to control mosquitoes have resulted in a decrease of malaria cases, WHO nonetheless estimates that 219 million individuals were infected in 2010, of which 660,000 died, predomi- nantly in Africa [8].}

Yet, vector-borne diseases are also a threat to public health in Europe. Mounting an effective public health response can counteract challenges posed by them and protect humans from infections; dedicated activities such as disease and vector surveillance as well as monitoring infectious disease drivers (e.g. environmental or climatic conditions) can help to anticipate and to respond to emerging vector-borne diseases $[9,10]$.

Globalisation and environmental change; social and demographic change; and health system capacity are three interacting drivers that can set the stage for novel vector-borne disease scenarios [11]. The changing dynamic of these drivers can potentially create new constellations of threats that challenge control measures. Pathogens and vectors are bound to disseminate rapidly through globalised transportation networks: over 100 million air travellers alone enter continental Europe annually, connecting it to international 'hot spots' of emerging infectious diseases [12]. A casein-point is the importation, establishment and expansion of the Asian tiger mosquito (Aedes albopictus), first recorded in Albania in the 1970s and subsequently in Italy in the 1990s. The mosquito was imported in used car tires from the United States into Genova and Venice, both in Italy, from where the mosquito spread [13]. Dedicated vector surveillance activities (Figure 1) have documented that the vector has expanded due to permissive climatic and environmental conditions and is now established in numerous regions in Europe.

Astute surveillance activities were able to detect the autochthonous transmission of Chikungunya and dengue viruses by $A e$. albopictus in Europe triggered by infected travellers returning from endemic areas [13, 14]. Through vector surveillance, Ae. aegypti mosquitoes, the main vectors of dengue, were first detected in Madeira, Portugal in 2005 where they dispersed across the southern coastal areas of the island. From September 2012 to January 2013, the island experienced a large dengue outbreak, affecting more than 2,100 individuals, including 78 cases exported to continental Europe; the responsible dengue virus serotype DEN-1 was traced back to a probable Central or South American origin [15].

In December 2013, public health surveillance confirmed the first local transmission of Chikungunya virus in the Caribbean. Within three months the virus spread from Saint Martin island to six other neighbouring islands and autochthonous transmission was even reported in French Guiana, South America. Cassadou et al. and Omarjee et al. in this issue describe the importance of proactive public health practice during such a vectorborne disease emergence [1]. Chikungunya infections were identified in a cluster of patients suffering from a febrile dengue-like illness with severe joint pain and who tested negative for dengue. The outbreak illustrates the importance of a preparedness plan with awareness of healthcare providers, adequate laboratory support for early pathogen identification, and 
Currently known vector surveillance activities in Europe, January 2014

Invasive mosquitoes

Currently known surveillance: January 2014 Yes $\square$ No

$\square$ No data

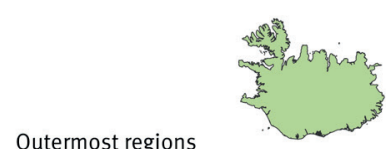

Outermost regions $\square$ Azores (PT) $\square$ Canary Islands (ES) Madeira (PT) $\square$ Svalbard/Jan Mayen (NO)
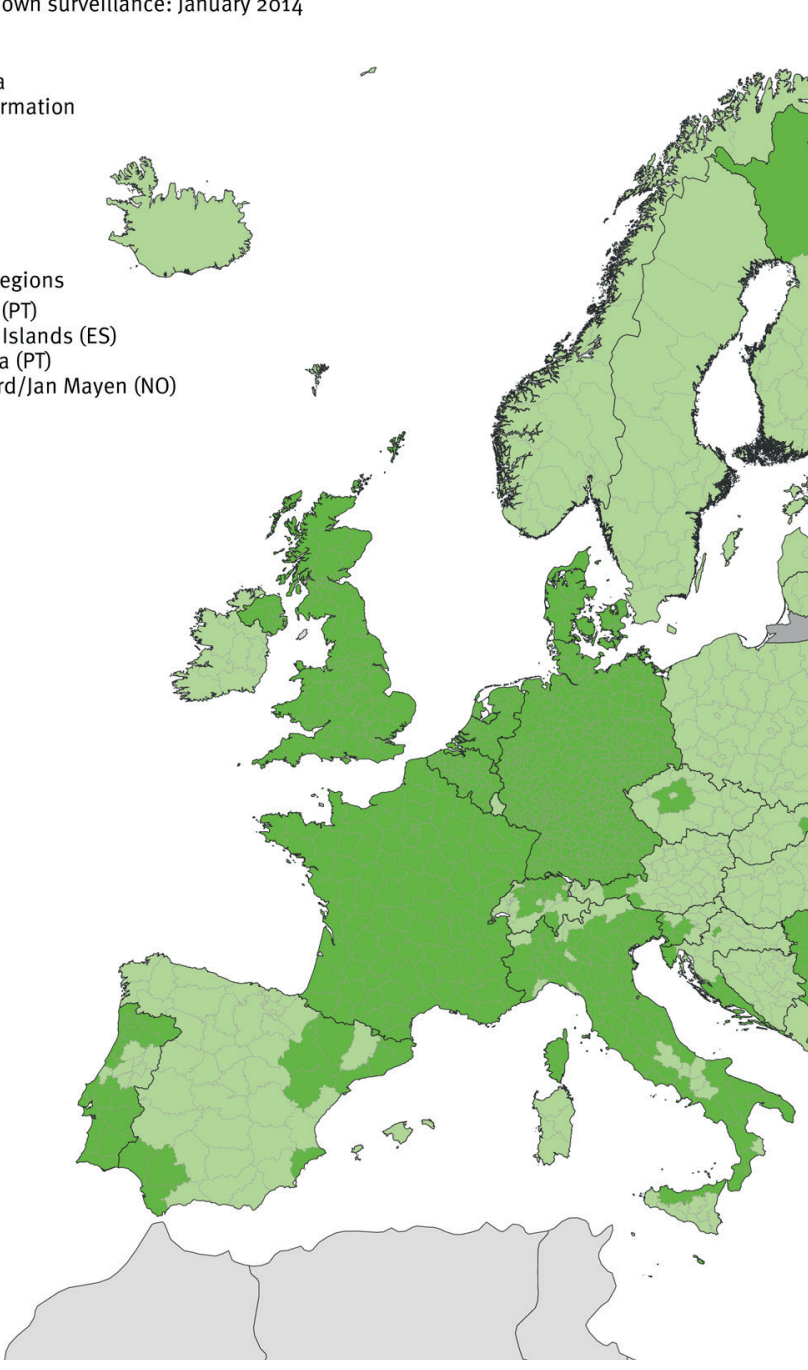

The surveillance activities include not only specific surveillance studies but also work done as part of on-going control activities, research projects and inventory studies.

Source: European Center for Disease Prevention and Control, 2014 [25].

appropriate response. Incidentally, in the past, several imported cases of Chikungunya fever were reported but did not result in local transmission or spread to surrounding islands.

Zika virus, transmitted by Ae. aegypti mosquitoes and originated from Africa and Asia emerged in French Polynesia in September 2013 and posed another health threat by Ae. albopictus mosquitos [16]. In this issue, Musso et al. report the first evidence of perinatal transmission of the Zika virus [2].

The parasitic mosquito-borne disease malaria was once common mainly in southern parts of Europe. While it had been eliminated largely via sanitary measures, local transmission has sporadically returned to Europe in recent years and cases from endemic countries continue to be routinely imported into Europe via travelers. In Greece, malaria had been eliminated in 1974 but starting in summer 2009 through 2012, locally acquired cases of Plasmodium vivax occurred in the summer months, mostly due to multiple re-introductions of the parasite [14]. The continuous spread of $P$. vivax by local anopheline mosquitoes raised the possibility of a sustained malaria transmission. In order to guide malaria control, areas with suitable environments for persistent transmission cycles were identified through multivariate modelling of environmental variables [17]. With information about this environmental fingerprint and using European Union (EU) structural funds, adequate measures could be taken and transmission in these areas was interrupted. Targeted epidemiological and entomological surveillance, vector abatement activities, and awareness raising among the 
general public and health workers proved to be successful to this effect.

A further important viral vector-borne disease is West Nile fever (WNF). It was first recognised in Europe in the 1950 s and re-emerged in Bucharest in 1996 and Volgograd in 1999 [13, 14]. Since then, several countries experienced limited outbreaks until 2010, when Europe witnessed an unprecedented upsurge in the numbers of WNF cases [18]. Ambient temperature deviations from a thirty year average during the summer months correlated with a WNF outbreak of over 1,000 cases in newly affected areas of south-eastern Europe [19]. Since the emergence of WNF in Greece in 2010, the disease has spread in the country reaching both rural and urban areas. In the subsequent summers from 2011 to 2013, the outbreaks did not subside in these areas. An article by Pervanidou et al. in the current issue describes the third consecutive year of autochthonous West Nile virus transmission in Greece [3]. It is a descriptive analysis of the 2012 outbreak, confirming risk factors such as advanced age, for severity of disease and medical risk factors such as chronic renal disease, for mortality from WNF.

Temperature determines viral replication rates, growth rates of vector populations and the timing between blood meals, thereby accelerating disease transmission [18]. With global climate change on the horizon, rising temperatures might be a climatic determinant of future WNV transmission that can be used as an early warning signal for vector abatement and public health interventions [13].

\section{Tick-borne diseases}

Tick-borne diseases are also of public health concern in Europe. Tick-borne encephalitis (TBE) is endemic in Europe and due to its medical significance was recently added to the list of notifiable diseases with a harmonised case definition focussing on neuroinvasive illness with laboratory confirmation [20]. The main vector of TBE, Ixodes ricinus, is widely distributed in Europe while TBE virus transmission is restricted to specific foci. Integrated surveillance is important to precisely determine these locations of active transmission to humans to better assess the risk and inform the public about adequate preventive measures which include protective clothing as well as vaccination. Schuler et al. in this issue describe the epidemiological situation of TBE in Switzerland over a five year period, showing the heterogeneity of the incidence according to cantons and the importance of the surveillance and vaccination as a preventive measure [4].

Tick activity is determined by ecological environmental conditions [21]. TBE incidence has been affected by both climatic and socio-demographic factors [13]. The political changes in the $1990 \mathrm{~s}$ after the dissolution of the former Soviet Union, might have contributed to the transmission of TBEV in the Baltic countries (Estonia, Latvia and Lithuania) and in eastern Europe by increasing the vulnerabilities for some population subgroups. A case control study from Poland found that spending extended periods of time in forests harvesting forest foods such as mushrooms, being unemployed or employed as a forester significantly increased the risk for TBE infections [22]. In central Europe, climate change-related temperature rise has been linked to an expansion of TBE virus transmitting ticks into higher altitude [23].

Lyme borreliosis, another endemic tick-borne disease, is believed to be the vector-borne disease with the highest burden in Europe. Climate change may be affecting the risk of Lyme borreliosis in Europe [13]; it has already been demonstrated that Borrelia transmitting ticks have been associated with an expansion into higher latitudes in Sweden [24].

Collectively, these examples demonstrate that vectorborne diseases remain an important challenge to public health in Europe. Monitoring environmental and climatic precursors of vector-borne diseases linked to integrated surveillance of human cases and vectors can help counteract potential impacts [9, 10]. Certainly, raising awareness and increasing knowledge among the general public, public health practitioners, and policy makers about disease vectors and their relationship with infectious diseases remains a priority also. Exposure prevention through personal protection and vector abatement are important components of effective intervention strategies. In addition, integrated vector surveillance of invasive and endemic mosquito species is crucial for effective prevention and control of vector-borne diseases.

\section{References}

1. Cassadou S, Boucau S, Petit-Sinturel M, Huc P, Leparc-Goffart I, Ledrans M. Emergence of chikungunya fever on the French side of Saint Martin island, October to December 2013. Euro Surveill. 2014;19(13): pii=20752.

2. Besnard $M$, Lastère $S$, Teissier $A$, Cao-Lormeau VM, Musso D. Evidence of perinatal transmission of Zika virus, French Polynesia, December 2013 and February 2014 . Euro Surveill. 2014;19(13): $\mathrm{pii}=20751$.

3. Pervanidou D, Detsis M, Danis K, Mellou K, Papanikolaou E, Terzaki I, Baka A, Veneti L, Vakali A, Dougas G, Politis C, Stamoulis K, Tsiodras S, Georgakopoulou T, Papa A, Tsakris A, Kremastinou J, Hadjichristodoulou C. West Nile virus outbreak in humans, Greece, 2012: third consecutive year of local transmission. Euro Surveill. 2014;19(13):pii=20758.

4. Schuler M, Zimmermann H, Altpeter E, Heininger U. Epidemiology of tick-borne encephalitis in Switzerland, 2005 to 2011. Euro Surveill. 2014;19(13): pii=20756.

5. Van Bortel W, Dorleans F, Rosine J, Blateau A, Rousseau D, Matheus S, Leparc-Goffart I, Flusin O, Prat CM, Césaire R, Najioullah F, Ardillon V, Balleydier E, Carvalho L, Lemaître A, Noël H, Servas V, Six C, Zurbaran M, Léon L, Guinard A, van den Kerkhof J, Henry M, Fanoy E, Braks M, Reimerink J, Swaan C, Georges R, Brooks L, Freedman J, Sudre B, Zeller H. Chikungunya outbreak in the Caribbean region, December 2013 to March 2014, and the significance for the European Union. Euro Surveill. 2014;19(13): $\mathrm{pii}=20759$.

6. Omarjee R, Prat CM, Flusin O, Boucau S, Tenebray B, Merle 0 , et al. Importance of case definition to monitor ongoing outbreak of chikungunya virus on a background of actively circulating dengue virus, St Martin, December 2013 to January 2014. Euro Surveill. 2014;19(13): pii=20753.

7. Bhatt S, Gething PW, Brady OJ, Messina JP, Farlow AW, Moyes $\mathrm{CL}$, et al. The global distribution and burden of dengue. Nature 2013; 496(7446): 504-7. http://dx.doi.org/10.1038/nature12060 
8. World Health Organization (WHO). Factsheet on the World Malaria Report 2012. [Accessed 28 Mar 2014] Available from: http://www.who.int/malaria/media/ world_malaria_report_2012_facts/en/.

9. Semenza JC, Sudre B, Oni T, Suk JE, Giesecke J. Linking environmental drivers to infectious diseases: the European environment and epidemiology network. PLoS Negl Trop Dis 2013; 7(7): e2323. http://dx.doi.org/10.1371/journal. pntd.0002323

10. Nichols GL, Andersson Y, Lindgren E, Devaux I, Semenza JC. European Monitoring Systems and Data for Assessing Environmental and Climate Impacts on Human Infectious Diseases. Int J Environ Res Public Health 2014; 11 (forthcoming).

11. Suk JE, Semenza JC. Future infectious disease threats to Europe. Am J Public Health. 2011; 101(11): 2068-79. http:// dx.doi.org/10.2105/AJPH.2011.300181

12. Jones KE, Patel NG, Levy MA, Storeygard A, Balk D, Gittleman $\mathrm{JL}$, et al. Global trends in emerging infectious diseases. Nature. 2008; 451(7181): 990-3. http://dx.doi.org/10.1038/ nature06536

13. Semenza JC, Menne B. Climate change and infectious diseases in Europe. Lancet Infect Dis 2009; 9(6): 365-75. http://dx.doi. org/10.1016/S1473-3099(09)70104-5

14. Zeller H, Marrama L, Sudre B, Van Bortel W, Warns-Petit E. Mosquito-borne disease surveillance by the European Centre for Disease Prevention and Control. Clin Microbiol Infect. 2013; 19(8): 693-8. http://dx.doi.org/10.1111/1469-0691.12230

15. Alves MJ, Fernandes PL, Amaro F, Osorio H, Luz T, Parreira $P$, et al. Clinical presentation and laboratory findings for the first autochthonous cases of dengue fever in Madeira island, Portugal, October 2012. Euro Surveill. 2013;18(6):pii=20398.

16. Wong PS, Li MZ, Chong CS, Ng LC, Tan CH. Aedes (Stegomyia) albopictus (Skuse): a potential vector of Zika virus in Singapore. PLoS Negl Trop Dis. 2013; 7(8): e2348. http:// dx.doi.org/10.1371/journal.pntd.0002348

17. Sudre B, Rossi M, Van Bortel W, Danis K, Baka A, Vakalis N, et al. Mapping environmental suitability for malaria transmission, Greece. Emerg Infect Dis. 2013; 19(5): 784-6. http://dx.doi. org/10.3201/eid1905.120811

18. Paz S, Semenza JC. Environmental drivers of West Nile fever epidemiology in Europe and Western Asia--a review. Int J Environ Res Public Health. 2013; 10(8): 3543-62. http://dx.doi. org/10.3390/ijerph10083543

19. Paz S, Malkinson D, Green MS, Tsioni G, Papa A, Danis K, et al. Permissive summer temperatures of the 2010 European West Nile fever upsurge. PLoS One. 2013; 8(2): e56398. http:// dx.doi.org/10.1371/journal.pone.0056398

20. Amato-Gauci AJ, Zeller H. Tick-borne encephalitis joins the diseases under surveillance in the European Union. Euro Surveill. 2012;17(42): $\mathrm{pii}=20299$.

21. Medlock JM, Hansford KM, Bormane A, Derdakova M, Estrada-Pena A, George JC, et al. Driving forces for changes in geographical distribution of Ixodes ricinus ticks in Europe. Parasit Vectors. 2013; 6: 1. http://dx.doi. org/10.1186/1756-3305-6-1

22. Stefanoff $P$, Rosinska M, Samuels S, White DJ, Morse DL, Randolph SE. A national case-control study identifies human socio-economic status and activities as risk factors for tickborne encephalitis in Poland. PLoS One. 2012; 7(9): e45511. http://dx.doi.org/10.1371/journal.pone.0045511

23. Daniel M, Materna J, Honig V, Metelka L, Danielova V, Harcarik $J$, et al. Vertical distribution of the tick Ixodes ricinus and tick-borne pathogens in the northern Moravian mountains correlated with climate warming (Jeseniky Mts., Czech Republic). Cent Eur J Public Health. 2009; 17(3): 139-45.

24. Lindgren E, Talleklint L, Polfeldt T. Impact of climatic change on the northern latitude limit and population density of the disease-transmitting European tick Ixodes ricinus. Environ Health Perspect. 2000; 108(2): 119-23. http://dx.doi. org/10.1289/ehp.00108119

25. European Centre for Disease Prevention and Control (ECDC). Available from: http://www.ecdc.europa.eu/en/healthtopics/ vectors/vector-maps/Pages/VBORNET_maps.aspx 